\title{
Relationship Between Grades Earned and Time in Online Courses
}

\author{
Lin B. Carver, Keya Mukherjee and Robert Lucio \\ Saint Leo University
}

\begin{abstract}
Online education is rapidly becoming a significant method of course delivery in higher education. Consequently, instructors analyze student performance in an attempt to better scaffold student learning. Learning analytics can provide insight into online students' course behaviors. Archival data from 167 graduate level education students enrolled in 4 different programs and 9 different online courses were analyzed to determine whether a relationship existed between grades earned and time spent in specific areas within the course: total course time, course modules, document repository, and synchronous online sessions. Time spent in each component did not predict a specific letter grade, but did predict whether or not an A would be achieved. The sample was composed of students from four different graduate education programs: Educational Leadership, Reading, Instructional Design, and Special Education. Variations found among programs did not significantly predict the grade earned in the course. A logistic regression revealed that of all the predictor variables, time spent in synchronous online sessions alone showed as a significant predictor of receiving an $\mathrm{A}$ in the course. This is important information for instructors when providing scaffolding for students.
\end{abstract}

Keywords: student success, synchronous, learning analytics

Carver, L. B., Mukherjee, K., \& Lucio, R. Relationship between grades earned and time in online courses. Online Learning, 21(4), 303-313. doi: 10.24059/olj.v21i4.1013

\section{Relationship Between Grades Earned and Time in Online Courses}

\section{Growth in Online Courses}

Online education plays a significant role in higher education, especially among adult learners at the university level (Jo, Kim, \& Yoon, 2015). The majority of American college courses have some digital components, ranging from the fully online to Web enhanced. Consequently, digital learning has become an integral part of instructional delivery in much of higher education (Ciabocchi, Ginsberg, \& Picciano, 2016).

As of 2016, Allen and Seaman (2016) reported that there were between 5.5 and 7 million higher education students enrolled in at least one online course. This was more than a $100 \%$ 
increase from the total just six years previously (Allen \& Seaman, 2010). Although both graduate and undergraduate courses are offered online, graduate students have found this format to be particularly advantageous because of reduced time constraints allowing adult learners a more flexible schedule (Putman, Ford, \& Tancock, 2012).

Studies comparing online learning and face-to-face instruction revealed that research since 1998 had recorded better learning outcomes from online courses than from face-to-face courses (Zhao, Lei, Yan, Lai, \& Tan, 2005). Zhao et al.'s findings suggested that the technological advances which enhanced two-way interaction might promote this online advantage. Means, Toyama, Murphy, Bakia, and Jones (2009), in their analysis of 56 rigorous studies of online education, found that learners in online settings significantly outperformed their peers in face-toface settings in the use of metacognitive strategies. These skills included self-reflection, selfexplanation, and self-monitoring.

Expanded technological support and enhanced online learning experiences offered through learning tools within Learning Management Systems (LMS) have significantly improved learning in online courses. Since the late 1990s, approximately 93\% of surveyed U.S. higher education institutions (Campus Computing, 2010) report having adopted web-based LMS to deliver online learning courses. In another study, almost $94 \%$ of survey participants from 417 colleges and universities stated that "digital curricular resources make learning more efficient and effective for students" (Campus Computing, 2015, para. 1) and 96\% of surveyed institutions agreed that "adaptive learning technology has great potential to improve learning outcomes" (Campus Computing, 2015, para. 1).

\section{Student Performance in Online Courses}

Even though performance and use of metacognitive strategies are effective in the online environment, online learners tend to face additional challenges. Without the support of a structured classroom environment, online learners frequently face time management issues caused by juggling the demands of course work, employment, and other responsibilities despite the presence of learning and collaborative tools. Consequently, successful completion of online course work can be impacted by learners' time management skills (Joo, Jang, \& Lee, 2007). Another component that could affect performance in online learning is the sense of community. Course components such as real-time lectures and group discussions using web conferencing tools might enhance online course experiences. Real time student-to-student and student-to-teacher interactions (Falloon, 2011; Pattillo, 2007) help build an important sense of community (Hrastinski, 2008). The extent to which students are using the various tools provided for them in the online environment can be examined using learner analytics data that are available within the LMS. This information can guide professors to understand typical patterns of student usage and their correlation to student grades. However, the usefulness of learning analytics to an institution depends upon data availability through their LMS and instructors' ability to analyze the data. This analytic information varies and is not necessarily incorporated into a coherent, widely understood plan or strategy for data use and interpretation (West \& Heath, 2016).

\section{Analytics: A data mining tool}

Learning analytics is a tool embedded in a Learning Management System for "the measurement, collection, analysis, and reporting of data about learners and their contexts, for purposes of understanding and optimizing learning and the environments in which it occurs" (Long $\&$ Siemens, 2011, p. 32). This tool, according to Campbell, DeBlois, and Oblinger (2017), produce 
"actionable intelligence" for use by the institution and is therefore frequently used for enrollment and other administrative purposes; however Macfadyen and Dawson (2012) and Picciano (2012) determined that analytics can provide a detailed understanding of how students spent time in LMSsupported courses related to the usage of the tools and pedagogical strategies employed by the learners and how the data can be used to form conclusions to improve learning. The data provide information about specific variables that enhance educational opportunities, thereby allowing instructors to intervene when students are at risk or to provide additional feedback and instructional content when appropriate (Avella, Kebritchi, Nunn, \& Kanai, 2016).

Because online course format can result in isolated learners, research has emphasized the importance of developing peer interaction to facilitate learning (Tinto, 1998). In order to examine peer to peer interaction, Dawson et al. (2008) analyzed the types and frequency of interactive tools used within the LMS. They found that measuring the average time that a learner spends online using an LMS provided merely "a crude indicator of student time investment in learning" (Macfadyen \& Dawson, 2012, p. 153). Student engagement has been examined in many studies. Graduate and undergrad students have been found to have differing reactions to the importance of various components within online courses. Schroeder, Baker, Terras, Mahar, and Chiasson (2016) noted that graduate students desired connectivity with their instructors but connectivity with other students was not viewed as important, while undergrad students viewed both as important. Carver et al. (2013) noted that the most important factor in using synchronous sessions for graduate students was not simply adding the sessions to the course, but to specifically use the sessions to support and expand course content. The difference in perspective between graduate and undergraduate students might be a significant contributing factor affecting voluntary attendance at synchronous sessions within this study.

To further analyze what students were doing while logged into LMS-based course sites, data from the LMS tool usage can be analyzed. Macfadyen and Dawson (2012) divided the online tools into four broad categories: Engagement with Learning Community, Working with Content, Assessment, and Administrative Tasks. Their sample of almost 4,000 graduate and undergraduate course sections indicated that students used tools from the Working with Content category than they did in the other categories, which resulted in a significant correlation between student use of tools with the Working with Content category and students' final course grade. However, they also found a significant positive correlation between increased use of tools in the Engagement with Learning Community category and academic success (Macfadyen \& Dawson, 2010). They found a significant positive correlation between students' final grade in the course and their use of the tools within the Engagement with Learning Community category. This category included use of the discussion boards and the course email (Macfadyen \& Dawson, 2010). Previously, Dawson, McWilliam, and Tan (2008) had only identified a significant positive correlation with first year college science students between final grades and students' use of course content materials. The research questions in our study attempted to determine whether the same conclusion applied to graduate students.

Research has determined that learning analytics can be used to help instructors determine student learning outcomes as well as to determine how to improve student's academic performance (Bhardwaj \& Pal, 2011). In an attempt to further analyze what student were doing while logged into LMS-based course sites, the current research study examined data on LMS tool usage. In the current research study, the researchers examined the online course analytics from graduate level courses in the Department of Education at a four-year private university. The areas analyzed 
included: total time in course, time spent in the content module, the document repository, and the online synchronous sessions. This study examined two of Dawson et al.'s (2008) four areas: Working with Content (content modules and document repository) and Engagement (ClassLive) more extensively to determine the effects of usage of these tools on final course grade. Based on increasing evidence that student engagement with peers in a learning community has a strong positive correlation with learning success, the researchers wanted to specifically examine these two categories. It was hypothesized that there would be a significant correlation between the various LMS elements, amount of time spent within the online course the modules, the document repository, and the synchronous online tool, and whether a graduate student earned an A in the course (Macfadyen \& Dawson, 2010).

\section{Research Questions}

For this study, the researchers used the following research question to guide the study: What relationship exists between the total amount of time graduate students spend in the various online course elements - total time within course, course modules, document repository, and synchronous online tool - and whether the student earned an A in the course?

$H_{01}$ : In an online course, there will be not be a relationship between total time spent in the course, in the course modules, synchronous online class sessions, or the document repository and the grade earned in the course.

$H_{A 1}$ : In an online course, there will be a significant relationship $(p \leq .05)$ between total time spent in the course, in the course modules, synchronous online class sessions, or the document repository and the grade earned in the course.

$H_{02}$ : In an online course, there will be not be a relationship between total time spent in the course, the course modules, synchronous online class sessions, or document repository and earning an $\mathrm{A}$ in the course.

$H_{A 2}$ : In an online course, there will be a significant relationship $(p \leq .05)$ between total time in course modules, synchronous online class sessions, or document repository and earning an $\mathrm{A}$ in the course.

$H_{03}$ : In an online course, there will not be a significant relationship $(p \leq .05)$ between the program and the time spent in the course modules, synchronous online class sessions, or the document repository and the grade earned in the course.

$H_{A 3}$ : In an online course, there will be a relationship $(p \leq .05)$ between the program and the time spent in the course modules, synchronous online class sessions, or the document repository and the grade earned in the course.

\section{Methods}

Learning analytics archival data from students enrolled in courses in four graduate programs in Education: Reading, Exceptional Education, Educational Leadership, and Instructional Design at a small southeastern university were analyzed to determine the relationship between the time students spent in various course elements and their final course grade.

Data from the LMS from 167 Master's level students enrolled in 10 course sections during the fall 2014 and the spring 2015 were analyzed (See Table 1). The sample included 47 students 
from the Reading program, 59 students were from the Educational Leadership program, 36 students were from the Exceptional Student Education program, and 25 students were from the Instructional Design program. To correct for variation among instructors, the sample included courses taught by seven different graduate education professors. However all of the sections were taught using master course syllabi and master course shells designed to incorporate the same elements. Each course, therefore, included eight common elements: content modules, a document repository for assignments and course related information, weekly discussion boards for student interactions related to the content, and weekly synchronous online class hours. The graduate students earned grades based upon the quality of the discussion postings, while no grade was attached to the modules, document repository, or synchronous components. The researchers acknowledge that online learners are limited in their ability to avail themselves of synchronous sessions because of constraints of time and geographical location; hence no part of the course grade was tied to participation in the synchronous sessions. Additionally, recorded sessions of the live sessions were made available to students immediately after the session for students to access at their convenience.

As these are graduate level courses, the numbers of students earning Cs, Ds, or Fs were negligible. A total of 123 students earned As, 34 students earned Bs, 7 students earned Cs, 2 students earned Ds and 1 students earned an F. The independent variables identified for the analysis were total time spent by students within the course LMS, time spent in the modules within the online classroom, time spent in the document repository area, and time spent in synchronous online sessions. The dependent variable used in the analysis was the course grade earned by the student. The demographic data by program and independent variable are provided in Table 1.

\begin{tabular}{|c|c|c|c|c|c|}
\hline & $\begin{array}{l}\text { Educational } \\
\text { Leadership } \\
(\mathrm{N}=123)\end{array}$ & $\begin{array}{c}\text { Instructional } \\
\text { Design } \\
(\mathrm{N}=25)\end{array}$ & $\begin{array}{l}\text { Reading } \\
(\mathrm{N}=47)\end{array}$ & $\begin{array}{c}\text { Special } \\
\text { Education } \\
(\mathrm{N}=36)\end{array}$ & $\begin{array}{c}\text { Total } \\
(\mathrm{N}=167)\end{array}$ \\
\hline $\begin{array}{l}\text { Total time within the } \\
\text { Course }\end{array}$ & $\begin{array}{l}90.1 \text { hours } \\
(\mathrm{SD}=46.2)\end{array}$ & $\begin{array}{l}84.8 \text { hours } \\
(\mathrm{SD}=46.8)\end{array}$ & $\begin{array}{l}75.8 \text { hours } \\
(\mathrm{SD}=46.8)\end{array}$ & $\begin{array}{l}96.7 \text { hours } \\
(\mathrm{SD}=44.9)\end{array}$ & $\begin{array}{l}86.7 \text { hours } \\
(\mathrm{SD}=43.9)\end{array}$ \\
\hline $\begin{array}{l}\text { Time spent in Synchronous } \\
\text { Online Sessions }\end{array}$ & $\begin{array}{l}2.3 \text { hours } \\
(\mathrm{SD}=2.5)\end{array}$ & $\begin{array}{l}2.0 \text { hours } \\
(\mathrm{SD}=1.6)\end{array}$ & $\begin{array}{l}2.9 \text { hours } \\
(\mathrm{SD}=2.4)\end{array}$ & $\begin{array}{l}2.4 \text { hours } \\
(\mathrm{SD}=1.9)\end{array}$ & $\begin{array}{l}2.5 \text { hours } \\
(\mathrm{SD}=2.3)\end{array}$ \\
\hline Time spent in the Modules & $\begin{array}{c}35 \text { hours } \\
(\mathrm{SD}=17.6)\end{array}$ & $\begin{array}{l}40.5 \text { hours } \\
(\mathrm{SD}=22.5)\end{array}$ & $\begin{array}{l}35.9 \text { hours } \\
(\mathrm{SD}=15.9)\end{array}$ & $\begin{array}{l}46.6 \text { hours } \\
(\mathrm{SD}=24.1)\end{array}$ & $\begin{array}{l}38.5 \text { hours } \\
(\mathrm{SD}=19.9)\end{array}$ \\
\hline $\begin{array}{l}\text { Time spent in Document } \\
\text { Repository }\end{array}$ & $\begin{array}{l}3.9 \text { hours } \\
(\mathrm{SD}=3.8)\end{array}$ & $\begin{array}{l}3.6 \text { hours } \\
(\mathrm{SD}=2.5)\end{array}$ & $\begin{array}{l}7.7 \text { hours } \\
(\mathrm{SD}=3.8)\end{array}$ & $\begin{array}{l}4.6 \text { hours } \\
(\mathrm{SD}=3.3)\end{array}$ & $\begin{array}{l}5.1 \text { hours } \\
(\mathrm{SD}=3.9)\end{array}$ \\
\hline Percent Earning an A & $83.1 \%$ & $72.0 \%$ & $76.6 \%$ & $55.6 \%$ & $73.7 \%$ \\
\hline
\end{tabular}

Table 1. Demographic Information

A one-way ANOVA was used to analyze significant differences in time spent within the portions of the course and the student's final grade. The ANOVA revealed that there was a significant difference based on the total time within the course $(F(2,164)=6.93, p<.001)$, time spent in the synchronous online sessions $(F(2,164)=7.15, p<.001)$, and time spent within modules $(F(2,164)=6.65, p=.002)$ (Table 2). However, there were not significant differences based on time spend in document sharing, $(F(2,164)=1.08, p=.342)$.

Post-hoc analysis showed statistically significant differences between those students earning an A and those earning any other grade. However, no difference was found between 
students earning B, C, or below. It can be concluded, therefore, that time invested in the LMS did not seem to help distinguish between performances at different grade levels below an A. As a result, the data were merged into two groups: those students earning an A and those students who did not earn an A. T-tests were then used to confirm whether there was a difference between the mean time spent in each area when compared to those students who earned an A and those who did not earn an $\mathrm{A}$. The difference between the mean time spent in the document repository of those earning an $\mathrm{A}$ and those not earning an $\mathrm{A}$ was not significant.

\begin{tabular}{lccc}
\hline & $\begin{array}{c}\text { Earning an } \mathbf{A} \\
(\mathbf{N}=\mathbf{1 2 3})\end{array}$ & $\begin{array}{c}\text { Not Earning an A } \\
\mathbf{( N = 4 4 )}\end{array}$ & P Value \\
\hline Total time within the Course & 93 hours & 67.2 hours & $.001^{*}$ \\
& $(\mathrm{SD}=46.1)$ & $(\mathrm{SD}=30.2)$ & \\
\hline Time spent in Synchronous Online & 2.8 hours & 1.4 hours & $.001^{*}$ \\
Sessions & $(\mathrm{SD}=2.3)$ & $(\mathrm{SD}=1.8)$ & \\
\hline Time spent in the Modules & 41.5 hours & 24.7 hours & $.002^{*}$ \\
& $(\mathrm{SD}=20.7)$ & $(\mathrm{SD}=14.9)$ & \\
\hline Time spent in Document Repository & 5.25 hours & 4.68 hours & .342 \\
& $(\mathrm{SD}=3.8)$ & $(\mathrm{SD}=4.3)$ & \\
\hline
\end{tabular}

P* denotes probability

Table 2. Results comparing mean times between earning an A and not earning an A

Since the analytics data were analyzed and compared from 4 different programs, the researchers also wanted to determine whether the program (Reading, Exceptional Student Education, Educational Leadership, or Instructional Design) impacted the results. An ANOVA was performed which revealed differences between the program the student was enrolled in, the amount of time spent in the document repository $(F(3,163)=11.91, p<.001)$, and time spent in the 8 content modules $(F(3,163)=3.046, p=.030)$. Sheffe's post-hoc follow up analysis showed that students in Educational Leadership spent more time in the modules than Reading students, while Reading students spent more time in document sharing than students in all other programs. There seem to be slight differences in the ways each program used the various components of the LMS. Additionally, it was found that grade distribution also differed by program with $83.1 \%$ of Educational Leadership students receiving an A, followed by Reading (76.6\%), Instructional Design $(72.0 \%)$, and Special Education $(55.6 \%), \chi^{2}(3,167)=9.01, p=.029$. In addition to time spent in modules and student grade distribution, program enrollment was included in further analysis in order to determine the effect of the synchronous online session time and time spent in content modules above and beyond the effect of program type.

A logistic regression was conducted to predict the probability of receiving an $\mathrm{A}$ in a Masters level education course (Table 3). In Model 1, program type was entered as a covariate to control for the effect of the program in which students were enrolled in order to get a baseline model. The logistic regression used in Model 2 included the predictor variables of total time in course, synchronous online session time, time spent in course modules, and time spent in the document repository. Finally, Model 3 included both the covariate and predictor variables, which significantly predicted whether students received an A or a different grade in the course, $\chi^{2}(3,167)$ $=36.86, p<.001$. Of all the predictor variables, only time spent in synchronous online sessions showed as a significant predictor of receiving an A. 


\begin{tabular}{|c|c|c|c|c|c|c|c|c|c|}
\hline \multirow[b]{2}{*}{ Predictor } & \multicolumn{3}{|c|}{$\begin{array}{l}\text { Model } 1 \\
\text { Odds }\end{array}$} & \multicolumn{3}{|c|}{$\begin{array}{c}\text { Model } 2 \\
\text { Odds }\end{array}$} & \multicolumn{3}{|c|}{$\begin{array}{r}\text { Model } 3 \\
\text { Odds }\end{array}$} \\
\hline & $\beta(\mathrm{SE})$ & Ratio & $95 \% \mathrm{CI}$ & $\beta(\mathrm{SE})$ & Ratio & $95 \% \mathrm{CI}$ & $\beta(\mathrm{SE})$ & Ratio & $95 \% \mathrm{CI}$ \\
\hline Intercept & $\begin{array}{l}.223 \\
(.34)\end{array}$ & 1.25 & & $-.495(.48)$ & & & $-2.18(.71)$ & .114 & \\
\hline Program & & & & & & & & & \\
\hline ID & $\begin{array}{c}1.366 \\
(.48)^{* *}\end{array}$ & 3.92 & $\begin{array}{l}1.52- \\
10.09\end{array}$ & & & & $2.057(.58)^{* *}$ & 7.83 & \\
\hline Reading & $\begin{array}{c}0.721 \\
(.56)\end{array}$ & 2.06 & $\begin{array}{c}0.69- \\
6.14\end{array}$ & & & & $1.204(.64)$ & 3.33 & \\
\hline Special Ed & $\begin{array}{l}0.962 \\
(.48)^{*}\end{array}$ & 2.62 & $\begin{array}{l}1.02- \\
6.72\end{array}$ & & & & $1.724(.61)^{*}$ & 5.61 & \\
\hline Course Total & & & & $.009(.01)$ & 1.01 & $\begin{array}{l}0.99- \\
1.03\end{array}$ & $.005(.01)$ & 1.01 & $\begin{array}{l}0.98- \\
1.03\end{array}$ \\
\hline $\begin{array}{r}\text { Synchronous } \\
\text { online } \\
\text { sessions }\end{array}$ & & & & $.296(.12)^{*}$ & 1.34 & $\begin{array}{l}1.06- \\
1.70\end{array}$ & $.339(.13)^{*}$ & 1.40 & $\begin{array}{l}1.08- \\
1.82\end{array}$ \\
\hline Module & & & & $.015(.02)$ & 1.02 & $\begin{array}{l}0.97- \\
1.06\end{array}$ & $.036(.03)$ & 1.04 & $\begin{array}{l}0.99- \\
1.09\end{array}$ \\
\hline Document & & & & $-.056(.05)$ & 0.95 & $\begin{array}{l}0.85- \\
1.05\end{array}$ & $-.093(.07)$ & 0.91 & $\begin{array}{l}0.80- \\
1.04\end{array}$ \\
\hline \multicolumn{10}{|l|}{$* \mathrm{p}<.05, * * \mathrm{p}<$} \\
\hline \multicolumn{10}{|c|}{ Model 1: $\chi^{2}(3,167)=8.65, p<.05, R^{2}=.074$ (Nagelkerke) } \\
\hline \multicolumn{10}{|c|}{ Model 2: $\chi^{2}(4,167)=21.52, p<.001, R^{2}=.177$ (Nagelkerke) } \\
\hline \multicolumn{10}{|c|}{ Model 3: $: \chi^{2}(7,167)=36.86, p<.001, R^{2}=.289$ (Nagelkerke) } \\
\hline
\end{tabular}

Table 3. Logistic Regression

\section{Conclusion}

Time invested in an online course is only one variable that can impact students' success. The results of this study supported Mcfadyen and Dawson's (2010) findings that time spent on the tools within an online course does not necessarily correlate with grades earned. Across all 4 programs, the mean time spent in 8 -week graduate courses was 86.7 hours with the majority of this time being spent within the course modules. However, it did not follow that the greater the amount of time spent within the course, the higher the grade earned. The data did not help to distinguish between the students earning a grade of A and those students earning less than an A. Consequently, the null hypothesis was accepted for our first research question.

$H_{01}$ : In an online course, there will be not be a relationship between total time spent in the course, in the course modules, synchronous online class sessions, or the document repository and the grade earned in the course.

An examination of the analytic data revealed that there was a difference in the amount of time invested by those who earned an A and those who did not earn an A. A statistically significant relationship existed among three of the components we examined. Total time in course, time spent in the content modules, and time within synchronous online sessions all had a significant correlation to earning an A as compared to not earning an A in the course. However, time spent in 
the document repository was not significant. Consequently, we rejected the second null hypothesis and accepted the alternate second hypothesis.

$H_{A 2}$ : In an online course, there will be a significant relationship $(p \leq .05)$ between total time in the course, in the course modules, synchronous online class sessions, or document repository and earning an $\mathrm{A}$ in the course.

Although there was a statistically significant relationship, using a logistic regression was particularly informative because it revealed that only time spent in synchronous online sessions appeared to predict whether a student would earn an A in the course. For every 20 minutes spent in a synchronous online session, the likelihood of earning an A increased by 1.4 times. This seems to indicate the value of providing synchronous teacher-student and student-student interaction, which supports Tinto's (1998) observation about the importance of peer-to-peer interaction. It is to be noted that attendance at the synchronous sessions was voluntary and grades were not associated with attendance.

Another observation from the analytics data was a slight difference in students' performances between programs. Out of the four programs, students in the Educational Leadership students were more likely to earn an A, while Special Education students were least likely to earn an A. This information cannot be generalized to determine if the variance is impacted by characteristics of students admitted to the program, or by variables in the construction of the online courses. This type of a study cannot be used to determine causality.

There were also programmatic differences between the means of time spent in each portion of the LMS. The mean differences by program between the time spent in various parts of the LMS might be indicative of variations in the ways that the portions of the courses were constructed by program. However, differences between programs were not as significant as the difference between those students earning an A and those not earning an A.

$H_{A 3}$ : In an online course, there will be a relationship $(p \leq .05)$ between the program and the time spent in the course modules, synchronous online class sessions, or the document repository and the grade earned in the course.

The logistic regression provided the most important information. This information could be used to help instructors support student performance. For every 20 minutes (.339 units of an hour) students spent in synchronous online sessions, it increased the likelihood of receiving an A by 1.4 times, regardless of graduate program. Instructors who are aware of this figure would be able to explain the benefits of the synchronous sessions to the students and thereby encourage student participation.

As the LMS analytics become even more sensitive, this increased information would allow researchers and instructors to examine online student behavior even more specifically. Improved analytic information could provide additional data to more proactively support students during online courses, rather than simply analyzing student activity after the course completion.

\section{Limitations and Further Study}

The results of the research indicate that student participation in various portions of the LMS as measured by the learning analytics has a significant positive relationship with student achievement in graduate level online courses. The data indicates that an increase in student participation, especially in online synchronous sessions, should translate into an increase in student achievement in graduate online courses. However, the findings of this study have limitations. As 
is true of any cross-sectional study, the results of this research establish the strength of the relationship between the variables but cannot prove that one variable is the cause of the change in the other variable. Thus, the study is limited by only being able to show an inter-variable, rather than causal, relationship. Additionally, time spent in the course, modules, or synchronous online learning only provide information about amount of time logged into each activity, not what occurred during that time. Further studies should look at other measures of engagement which capture involvement in learning activities, which could help to identify which aspects of student activity during logged in time are most beneficial to students. Finally, additional, confounding variables may impact the relationship among variables under study (Mitchell, 1985).

This study raises further questions about the exact factors that make the synchronous online sessions within the courses so significant. Further study of the components of the synchronous sessions and how they are used within each of the programs would provide instructors with valuable information for better scaffolding the student learning experience. The results of this study cannot be generalized to other populations outside of the online graduate education students. The findings from this study might not be applicable to undergraduate students or those students enrolled in blended courses. 


\section{References}

Allen, E. \& Seaman, J. (2010). Learning on demand: Online education in the United States 2009. Needham, MA: Sloan Consortium.

Avella, J. T., Kebritchi, M., Nunn, S. G., \& Kanai, T. (2016). Learning analytics methods, benefits, and challenges in higher education: A systematic literature review. Online Learning, 20(4). Retrieved from http://olj.onlinelearningconsortium.org/index.php/olj/article/view/790/201

Bhardwaj, B. K., \& Pal, S. (2011). Data mining: A prediction for performance improvement using classification. International Journal of Computer Science and Information Security, 9(4), 136-140.

Campus Computing. (2010). The 2010 national survey of information technology in U.S. higher education. Retrieved from http://www.campuscomputing.net/sites/www.campuscomputing.net/files/GreenCampusComputing2010.pdf.

Campus Computing. (2015). The 2015 campus computing survey. Retrieved from http://www.campuscomputing.net/item/2015-campus-computing-survey-0

Carver, L., Todd, C., Hahn, K., \& Mukherjee, K. (2013). Students' perceptions of the effect of flipping online classes using a synchronous interactive online tool. Creative Education, 4(7A), 126-129. Retrieved from http://file.scirp.org/pdf/CE 2013071816214937.pdf

Ciabocchi, E., Ginsberg, A., \& Picciano, A. (2016). A study of faculty governance leaders' perception of online and blended learning. Online Learning, 20(3), 53-73. Retrieved from https://olj.onlinelearningconsortium.org/index.php/olj/article/view/974

Dawson, S., McWilliam, E., \& Tan, J. P.-L. (2008). Teaching Smarter: How mining ICT data can inform and improve learning and teaching practice. Paper presented at ASCILITE 2008, Melbourne, Australia.

Falloon, G. (2011). Making the connection: Moore's theory of transactional distance and its relevance to the use of a virtual classroom in postgraduate online teacher education. Journal of Research on Technology in Education, 43(3), 187-209.

Hrastinski, S. (2008). Asynchronous and synchronous e-learning. A study of asynchronous and synchronous e-learning methods discovered that each supports different purposes. Educause Quarterly, 31(4), 51-55.

Jo, I., Kim, D., \& Yoon, M. (2015). Constructing proxy variables to measure adult learners' time management strategies in LMS. Educational Technology \& Society, 18(3), 214-225.

Joo, Y., Jang, M., \& Lee, H. (2007). An in-depth analysis of dropout factors based on cyber university student's dropout experiences. The Journal of Educational Information Media, 13(3), 209-234. 
Macfadyen, L. P., \& Dawson, S. (2010). Mining LMS data to develop an "early warning system" for educators: A proof of concept. Computers \& Education, 54(2), 588-599. doi: 10.1016/j.compedu.2009.09.008

Macfadyen, L. P. \& Dawson, S. (2012). Numbers are not enough. Why e-Learning analytics failed to inform and institutional strategic plan. Educational Technology \& Society, 15(3), 149-163.

Means, B., Toyanna, Y., Murphy, R., Bakia, M., \& Jones, K. (2009). Evaluation of evidencebased practices in online learning: A meta-analysis and review of online learning studies. Washington, D.C.: U.S. Department of Education, Office of Planning, Evaluation, and Policy Development.

Mitchell, T. R. (1985). An evaluation of the validity of correlational research conducted in organizations. Academy of Management Review, 10(2), 192-205.

Pattillo, R. E. (2007). Decreasing transactional distance in a web-based course. Nurse Educator, $32(3), 109-112$.

Picciano, A.G. (2012). The evolution of big data and learning analytics in American higher education. Journal of Asynchronous Learning Networks, 16 (3), 9-20.

Putman, S., Ford, K., \& Tancock, S. (2012). Redefining online discussions: Using participant stances to promote collaboration and cognitive engagement. International Journal of Teaching \& Learning in Higher Education, 24(2), 151-167.

Schroeder, S., Baker, M. Terras, K., Mahar, P. \& Chiasson, K. (2016). Students' desired and experienced levels of connectivity to an asynchronous, online, distance degree program. Online Learning, 20(3), 244-264. Retrieved from https://olj.onlinelearningconsortium.org/index.php/olj/article/viewFile/691/233

Simon, M., \& Goes, J. (2013). Dissertation and scholarly research: Recipes for success. Seattle, WA: Dissertation Success LLC.

Tinto, V. (1998). Learning communities: Building gateways to student success. The National Teaching and Learning Forum, 7(4).

West, D. \& Heath, D. (2016). Let's talk learning analytics: A framework for implementation in relation to student retention. Online Learning, 20(2). Retrieved from http://olj.onlinelearningconsortium.org/index.php/olj/article/view/792/202

Zhao, Y., Lei, J., Yan, B., Lai C., \& Tan, H. S. (2005). What makes the difference? A practical analysis of research on the effectiveness of distance education. Teachers College Record, 107(8), 1836-1884. 